\title{
Os meios de comunicação e o suicídio: uma breve genealogia da narrativa da própria morte*
}

\section{RESUMO}

Abordamos, em perspectiva genealógica, a questão do suicídio em relação com os meios de comunicação. $\mathrm{O}$ caso do jovem brasileiro que narrou o próprio suicídio na Internet é ponto de partida para investigarmos de que forma o ciberespaço interfere na criação de si. Para redimensionar o problema, tratamos de dois outros casos: a publicação, no século XIX, de "Os sofrimentos do jovem Werther", de Goethe - e a profusão de suicídios decorrentes dela - e a morte do roqueiro Kurt Cobain, em um século XX profundamente mediado pela cultura de massas. Sugerimos que o suicídio é, fundamentalmente, uma questão de biopolítica, em um contexto em que a mídia tem importante papel em nossa atualidade de medicina salvacionista.

\section{PALAVRAS-CHAVE}

suicídio

subjetividade

ciberespaço

\section{ABSTRACT}

The aim of this work is to approach, from a genealogical perspective, the issue of suicide and its relations with media devices. The case of a young brazilian man that recounted his own suicide on Internet is the starting point for us to investigate how cyberspace interferes with self-creation. To rethink this problem, we investigate two other cases: the publication, in nineteenth century, of Goethe's "The sorrows of young Werther" - and the suicide profusion that came with it - and the death of rocker Kurt Cobain, in a century profoundly mediated by mass culture. We suggest suicide is fundamentally a biopolitics issue, in a context in which media has an important rule in contemporary times of salvation medicine.

\section{KEY WORDS}

suicide

subjectivity

cyberspace

\section{leda Tucherman \\ Professora do Programa de Pós-Graduação em Comunicação da UFRJ/RJ/BR iedatucherman@gmail.com}

\section{Ericson Saint Clair}

Doutorando do Programa de Pós-Graduação em Comunicação pela UFRJ/RJ/BR

ericsonsaintclair@gmail.com
A revista Época de 11 de fevereiro de 2008 trazia na capa, em destaque, a seguinte chamada: 'A história dramática do menino que transmitiu o próprio suicídio na rede'. Na página do sumário, também com tratamento diferenciado, líamos: 'Suicídio na Internet: sites incentivam pessoas a se matar; conheça a história de Yoñlu, o garoto que narrou a própria morte na Internet'. Da página 90 até a 92 aparecia uma corajosa ${ }^{1}$ entrevista concedida pelo Dr. Mario Corso, psicanalista do adolescente que se suicidou, cujo nome verdadeiro era Vinicius Gageiro Marques, com ressalva para o subtítulo: 'Há um centro de valorização da morte na Internet'.

Além das inúmeras conversas que a divulgação desta história provocou, também gerou uma curiosa ressonância jornalística: primeiro a elaboração de uma reportagem na revista Galileu de abril do mesmo ano, cuja capa trazia com requintes de composição gráfica o título: 'Mal. com: o lado sombrio da Internet', realizada pela jornalista Juliana Tiraboschi; depois, uma matéria do conhecido colunista Zuenir Ventura, publicada no jornal O Globo, onde ele dizia ter sido motivado por tal matéria da Galileu a comentar as transformações do comportamento, especialmente jovem, a partir da WEB.

Neste contexto, parece interessante pensarmos certas costuras que alguns temas provocam no sentimento popular, como, por exemplo, a seguinte: se há "mal. com" na Internet, seria preciso censurá-la ou, pelo menos, tratar de controlá-la. Esta é uma armadilha que precisamos saber combater.

Indo por outro caminho, ainda que possa parecer estranho à primeira vista, poderíamos encontrar aí, mesmo que nos comova perder uma vida jovem em tempo real, uma resistência ao modelo de saúde e biopolítica que caracteriza nossa atualidade? Seria este suicídio compartilhado e assistido uma forma de "ciberativismo"? Seria, na terminologia deleuziana, a presença de máquinas de guerra contra o Aparelho de Estado, representado pela mídia oficial e/ ou de massa²?

Quando analisamos a reportagem da Galileu, é esta figura de uma produção de sentido independente que nos é apresentada. Vejamos o lead: ' Receitas de bomba. Blogs anoréxicos, fóruns racistas, manuais suicidas, mergulhamos no lado sombrio da Internet para entender porque este conteúdo se dissemina e como as comunidades 'do mal' são combatidas'. E o que se propõe é uma medida política para impedir a continuidade desta disseminação. Ora, se a reação que se enuncia é política, então a ação também o teria sido. Não é assim que pensamos as artes da guerra, suas táticas e estratégias? Ou então a revista, propondo uma medida política, foi 
quem deu ao acontecimento a dimensão de ser uma "guerrilha", o que nos parece uma opinião razoável.

As tentativas de se construir uma prática discursiva em que se vincula, por uma relação de causalidade direta, o ciberespaço à efetuação do suicídio, tornamse evidentes em trechos da matéria acerca da morte do adolescente:

Não foi a primeira vez que Vinícius tentou o suicídio. Mas foi a primeira vez que havia vozes torcendo para ele morrer. Dizendo como ele podia morrer. E, desta vez, ele morreu. No Suicídio.com só existe a exposição de um corpo, o da vítima. Aqueles que disseram "mate-se" são vozes sem materialidade, desmancham-se no ar (Época, 2008).

\section{Parece interessante pensarmos} certas costuras que alguns temas provocam no sentimento popular, como, por exemplo, a seguinte: se há "mal.com" na Internet, seria preciso censurá-la ou, pelo menos, tratar de controlá-la.

Em outras palavras, assume-se que, neste caso, a passagem de um suicídio em potência para um suicídio em ato se dá fundamentalmente por conta das conversações empreendidas no ciberespaço. Não mencionam, porém, as várias comunidades e fóruns de desestímulo ao suicídio. Aqui é interessante salientar a indicação foucaultiana de que toda formação discursiva estrategicamente torna visível somente o que se encaixa no sistema de dispersão dos discursos que obedecem a uma dada regularidade. No caso, tal regularidade se atesta na relação causal necessária entre ciberespaço e mal.

Para tratar deste tema com mais acuidade, podemos, ainda mais uma vez, seguir o conselho de Nietzsche, Foucault e seus comentadores: uma pequena genealogia sempre serve para desnaturalizar aparentes evidências, permitindo fraturar o presente e fazê-lo aparecer na multiplicidade que o constitui. Neste caso, temos dois elementos singulares e uma conexão para pensar: uma panorâmica mirada no suicídio como questão na nossa cultura, sua presença histórica em diferentes meios de comunicação, produzindo diferentes reações e diversos quadros culturais e sua relevância na nossa atualidade de vocação médico-salvacionista, assim como na WEB e no seu movimento de atuação.
Suicídio: um problema filosófico 'Só há um problema filosófico verdadeiramente sério: o suicídio'
Albert Camus- 0 Mito de Sísifo

Abstraindo-nos do caráter exclusivo que Camus parece conceder ao suicídio como sendo a mais importante e talvez única questão relevante, a seu ver, para a filosofia, é interessante lembrar que se trata efetivamente de um tema que atravessa a história dos sistemas de pensamento e que aparece, de maneira explícita ou de maneira metafórica, desde a filosofia platônica até os atuais pensadores da biopolítica.

Como é que o suicídio aparece nas sociedades ocidentais? Esta é a nossa questão mais relevante, já que estamos falando de formas de enunciação e visibilidade que encerram a historicidade das experiências reais e imaginárias de cada época. E, embora conheçamos muitas variações e nuances e alguns sistemas filosóficos que não encarnaram esta perspectiva ${ }^{3}$, vemos com freqüência o suicídio sendo considerado como, ao mesmo tempo, um crime contra Deus (o dono da vida), contra a natureza (interrompe seu curso) e contra a cidade (impedindo as contribuições que poderiam ser feitas por quem se retirou da vida). Sob outra premissa, considerado como mal, o que transforma a vida no modelo do bem, ele é um mal metafísico, um mal natural e um mal real.

No entanto, é bastante difícil integrá-lo em qualquer sistema em que duas idéias paralelas não estejam cotejando a sua leitura: a idéia de posse ou propriedade, que implica pensar na figura do corpo próprio, no contraste com corpo religioso e o corpo social, e as idéias correlatas de liberdade e vontade. Não foi outro o motivo de, por exemplo, David Hume, ligado a uma filosofia da liberdade subjetiva, que considerou o suicídio uma opção individual. Ou ainda Schopenhauer, o filósofo da vontade, que, considerando o tema, comparou o suicídio, para quem estivesse padecendo de dor intensa (o que inclui a dor espiritual, se conhecemos seu pensamento) a acordar de um pesadelo.

Ainda um dado semântico nos permite encontrar uma genealogia e uma historicidade para a questão: embora fosse tema desde muito cedo para a filosofia, a própria morte de Sócrates sendo a ele associada, a palavra suicídio aparece pela primeira vez no século XVII. Menciona-se uma controvérsia que atribui este surgimento ao tratado de um inglês, Sir Thomas Browne, "Religio Médici" de 1643 ou ao texto "Theologia Moralis Fundamentalis" do teólogo Caramuel. Só no final do século XVII começou a ser traduzido para as principais línguas européias; como exemplo, na língua francesa vai receber o reconhecimento quando surge como verbete do dicionário de 1762 da Academia.

Qual é a sua marca semântica? Uma conotação tão negativa que associa o termo "suicídio" ao termo "ho- 
micídio", considerando o ato de tirar a própria vida algo bastante próximo de ato de tirar a vida do outro, o que é demonstrativo do que mencionamos acima: corpo próprio, liberdade e vontade.

Nietzsche certamente dava-se conta desta costura, tal como nos dá a ver no discurso de Zaratustra sobre a morte livre, onde Zaratustra começa afirmando: 'Muitos morrem demasiadamente tarde e outros demasiadamente cedo. Ainda soa estranha a doutrina: 'morra no tempo certo!' Morra no tempo certo: assim ensinava Zaratustra' (Nietzsche, 2002, p.67). A explicação é clara: para Nietzsche, a morte natural não é livre ou racional, e assim ocorre em momento impróprio. A morte voluntária, deliberada, é uma escolha, e, portanto, ocorre sempre no momento oportuno.

\section{Nos afastamos do modelo} iluminista na sua matriz racionalista; afinal, pelo menos o mito do progresso como inarredável viés do tempo ficou comprometido com o Holocausto e as bombas de Hiroshima e Nagasáqui.

Certamente para os cientistas sociais, os terapeutas, os pais, os amigos e o conjunto dos atores do universo da comunicação, a escolha não seria racional, já que movida por dor, sofrimento, ausência de afetos ou vínculos, crises e patologias as mais variadas. O que certamente faz muito sentido. No entanto, talvez o que nos espante é que aquilo que não tem sentido não produz discursos articulados. Vale lembrar o belíssimo texto de Bataille sobre o Marquês de Sade, onde ele nos diz que o grande mérito de Sade foi dar voz à violência, que a cultura ocidental apresentava como mudo ou movido a grunhidos.

No entanto, há muitos sentidos presentes nesta morte e no seu debate: na menor hipótese podemos dizer que ela foi duplamente anunciada: nas tentativas anteriores e nas escolhas estéticas, as afinidades eletivas, do nosso adolescente.

\section{Suicídio e cultura do livro: o caso Werther, de Goethe}

Embora pareça tão espetacular, a morte de Yoñlu não é o primeiro suicídio que atrai a atenção para a "responsabilidade" dos meios de comunicação na disseminação e/ou estetização da morte auto-decidida. A literatura romântica nos fornece o primeiro exemplo:
Os sofrimentos do jovem Werther, de Goethe, em que uma paixão conturbada e profunda provoca a morte do protagonista com um tiro desferido por sua própria mão. O livro causou tamanho impacto entre os jovens que originou uma série de suicídios, levando os governos de alguns países a discutirem a hipótese de impedir sua publicação.

Este exemplo literário e psico-social é relevante neste texto. Costumamos chamar de pós-moderna, póshumana ou pós-histórica a nossa realidade atual e, neste batismo, acreditamos identificar as relações que ela teria com o seu próximo passado como tendo sido superadas radicalmente, quer dizer, nas suas raízes. Isto nos parece uma visão redutora: preferimos pensar que a Modernidade não foi homogênea em nenhum momento ou aspecto de sua experiência; nela podemos encontrar uma multiplicidade ${ }^{4}$ que teve pelo menos duas faces ou vertentes de forte presença que chamamos, achando não trair muito o seu projeto, de modernidade iluminista e modernidade romântica.

Sendo duas e apresentando-se em tensão, não temos a mesma relação com ambas: a iluminista oferecendo o contrato social, a idéia de coletivo e de cidadania, o mito do progresso centrado na racionalidade do espírito e do Estado; a outra, romântica, expressando-se como "Tempo, suspende teu vôo", dando voz a este indivíduo finito, que experimenta a desvinculação com a eternidade não como desejo de futuro mas como intensidade, entusiasmo ${ }^{5}$, mergulho em si mesmo.

Acreditamos que, possivelmente, nos afastamos do modelo iluminista na sua matriz racionalista; afinal, pelo menos o mito do progresso como inarredável viés do tempo ficou comprometido com o Holocausto e as bombas de Hiroshima e Nagasáqui, que nos horrorizam exatamente porque não podemos deixar de identificar planejamento, ousadia e sucesso nestes eventos que foram vitórias racionais de guerra e derrotas do espírito.

No entanto, o mesmo não poderíamos dizer em relação à modernidade romântica. Claro que não se trata de uma continuidade simples: preferimos pensar que entender a história implica integrar suas rupturas (como aconselha Foucault), mas, também em perceber deslocamentos, que são sucessões que, não representando cortes, reconfiguram certos desenhos. Em relação a esta modernidade romântica que inventou os indivíduos singulares e suas experiências subjetivas e sociais, percebemos certas semelhanças, ainda que analógicas. Quando lemos hoje comentários sobre as novas tribos pensamos, por exemplo, no clube dos Hashimins, do qual fazia parte Baudelaire; quando vemos a moda dos blogs não podemos esquecer os diários secretos modernos; quando traduzimos a estética da existência por uma nova experiência que, por uma associação com as biotecnologias, desnaturaliza os corpos, pode não ser muito hábil falar em estranheza entre estas duas configurações culturais, nosso tempo e a modernidade 
romântica. Afinal, o declínio do homem público e o surgimento de um narcisismo festejado já foi tematizado muito antes do surgimento dos primeiros computadores, sendo uma das marcas fortes do nosso mundo moderno, liberto das tradições.

Nossa genealogia assume como método esta premissa de uma genealogia por fazer: por isto nos parece razoável poder pensar em diferentes experiências culturais e suas idéias sobre a morte, seus meios de expressão e comunicação e a leitura que o mundo oficial e os indivíduos na prática concreta de suas existências fizeram destes links.

\section{Suicídio e cultura de massa: o caso Cobain}

Assim, pulando séculos e trocando o suporte do impresso para o audiovisual, encontramos outra figura emblemática, o roqueiro Kurt Cobain, cuja morte fez da sua vida mais do que a sua obra. Talvez ele seja a realização mais acabada nesta nova era da relação de dois eixos: o primeiro é o da contracultura, desprezando as regras do status quo e aderindo ao correlato modelo de drogas, sexo e rock and roll, em que a intensidade é o que se mede, desprezando, ou até mesmo cultivando, a idéia de risco, como ratifica um trecho de sua carta de suicídio: 'it's better to burn out than to fade away'. Desnecessário lembrar as reações indignadas, imputando a "este tal de rock and roll" inúmeros riscos sociais. O segundo eixo é mais sutil: convém lembrar que esta "morte anunciada" aumentou a venda e a audição dos seus discos, ironicamente transformando Cobain na figura mítica que ele dizia evitar tornar-se.

\section{Basta que se implemente um suicídio simbólico e se produza uma nova face: por detrás de uma máscara não há um rosto, mas sempre outra máscara.}

Se compusermos uma breve e certamente incompleta historicização da relação entre o rock and roll e a idéia de suicídio, encontramos sentidos diversos. Se, para o rock sessentista, hippie e humanista, o suicídio era ainda um tabu, nos anos 70 ele surge como reconhecimento de que o sonho havia terminado, passando a ser alvo de investimento simbólico por vários artistas. O inglês David Bowie, por exemplo, ao negar-se uma identidade fixa e ao assumir uma nova persona a cada LP lançado, trazia também para o universo pop a idéia de morte simbólica. Com a assunção de identidades descartáveis, Bowie sugere que o suicídio real é desnecessário. Basta que se implemente um suicídio simbólico e se produza uma nova face: por detrás de uma máscara não há um rosto, mas sempre outra máscara.

Entretanto, encontramos, também nos anos 70, o suicídio como tema constantemente explorado por bandas punk, cujo slogan "no future", imortalizado pelos ingleses do Sex Pistols, seria representativo de uma maneira de o jovem estar no mundo. Também nos anos 80, bandas como Joy Division e outras tematizam o suicídio a partir de um viés claramente soturno, normalmente vinculado a um consumo de cocaína excessivo e de posse de uma visão necessariamente sombria de um futuro que se vincula fortemente ao desenvolvimento frenético do capital e da impessoalidade, em que, segundo esta visão, não haveria espaço para a "felicidade".

Os anos 90 do Nirvana de Cobain e do movimento grunge de Seatle de certa forma prolongam tal abordagem do mal, permeada pela idéia do suicídio. Apresentam, também, um interessante ingrediente, que já era, aliás, fortemente característico do movimento punk: a ironia dos valores contemporâneos americanos, materializados na dicotomia "winner" ou "loser". Assumindo-se como "losers", os grunges pretendiam debochar do status quo, como no famoso refrão do hit Smells like teen spirit, do Nirvana: 'Here we are now, entertain us [...] I feel stupid and contagious'.

É preciso destacar, no que se refere à relação entre rock and roll e suicídio, que os anos 90 também assistem à ascensão da temática dos medicamentos relacionados às novas patologias psiquiátricas, tais como depressão, síndrome do pânico etc. Se, no movimento punk das décadas anteriores, o abuso dos medicamentos se encaixava em um imaginário de exploração dos próprios limites em um ambiente de puro tédio urbano (como no famoso trecho da música dos Ramones: 'Twenty-four hours ago I wanna be sedated, nothing to do, nowhere to go, I wanna be sedated'), nos anos 90 os medicamentos muitas vezes (mas não exclusivamente) aparecem como elementos materiais de garantia de uma existência menos dolorosa, como é o caso do cultuado Thom Yorke, vocalista da banda Radiohead, diagnosticado com depressão e um dos ídolos do adolescente que se suicidou na Internet.

Não importa, contudo, se tratamos do suicídio real de Kurt Cobain ou dos múltiplos suicídios simbólicos de David Bowie. O que para nós se mostra interessante é expor, mesmo muito brevemente, as múltiplas vozes que já trataram do tema do suicídio no universo da cultura de massas, aqui representada pelo microcosmo do rock and roll. Culpar o rock (ou qualquer produto de cultura de massa) por comportamentos indesejáveis dos jovens é não apenas ignorar a possibilidade de absorção criativa dos consumidores (como mostraram Michel de Certeau e outros) como também não atentar à pluralidade de discursos possíveis envolvendo as formas de expressão cultural. 


\section{Suicídio e biopoder: da modernidade ao contemporâneo cibercultural}

Porque é que o suicídio se transforma neste tipo de questão? Quando é que começa a receber a atenção oficial do mundo cultural e político? Para responder a esta provocação, vale o recurso ao hoje talvez mais célebre texto de Foucault, o último capítulo da História da Sexualidade I, A vontade do saber, Direito de morte e poder sobre a vida, nodal para pensar o biopoder, que acreditamos ser o sujeito do desejo de controle da Web como das edições etc:

Não deve surpreender que o suicídio - outrora crime, pois era um modo de usurpar o direito de morte que somente os soberanos, o daqui de baixo e o do além, tinham o direito de exercer, tenha-se tornado, no decorrer do século XIX, uma das primeiras condutas que entraram no campo da análise sociológica; ele fazia aparecer, nas fronteiras e nos interstícios do poder, o direito individual e privado de morrer (Foucault, 2006, p.151).

Então, a rigor, o suicídio foi, desde sempre, uma questão para o biopoder; uma infração individual em um poder que deve administrar a vida e evitar a morte, gerenciando mortalidade, natalidade, longevidade, reprodução e migrações. Mesmo sendo, ou talvez porque o seja, como quer Lacan, o único ato que definitivamente produz sentido, ele é um dos insuportáveis da nossa sociedade desde a sua modernidade histórica.

O suicídio foi um dos primeiros objetos de investigação da nascente sociologia do século XIX. Seu teórico mais conhecido, Émile Durkheim, buscou comprovar a importância da influência da sociedade no comportamento individual a partir de uma análise do suicídio rica em estatísticas e comparações entre grupos sociais diversos. Através desse método, indicou, por exemplo, que os católicos cometiam menos suicídio que os protestantes, dada a maior vigilância dos atos mais cotidianos que a Igreja empreendia sobre os fiéis. Por outro lado, a idéia do suicídio seria menos atraente aos homens casados do que aos solteiros. Grosso modo, Durkheim afirmou que o suicídio podia ser efeito tanto de uma estruturação social fraca, incapaz de vincular o indivíduo aos outros iguais, quanto de um excesso de estruturação social, que seria, ao contrário, tão presente na vida do indivíduo que o sufocaria.

Os trabalhos sociológicos sobre o tema feitos antes de O suicídio, livro de Durkheim de 1897, procuraram entendê-lo em relação ao crime, especialmente o homicídio, destacando-se o estudo de 1891 de Armand Corre intitulado Crime et suicide. Também sociólogo, o francês Gabriel Tarde publicou em 1892 em seu Étude pénales et sociales uma proposta de abordagem do suicídio sem vinculação direta ao homicídio, apesar de reconhecer tal ligação. O suicídio moderno seria, para
Tarde, mais um efeito de correntes contagiosas de imitação de determinadas crenças e desejos.

Afastando-nos da discussão sociológica e voltando a pensar com Nietzsche e Foucault, poderíamos considerar que nossa repulsa ao suicídio se insere muito bem no dispositivo biopolítico em vigência desde o final do século XVIII pelo menos. Ao depender de um médico para fazer continuar a vida, segundo Nietzsche, estamos enredados na 'miserável e terrível comédia que o cristianismo fez da hora da morte' (Nietzsche, 2006, p.84), que se aproveita do estado de fraqueza daquele que está morrendo para emitir juízos de valor sobre ele e seu passado. Os médicos, assim, deveriam negar prolongar essa 'vida que degenera'. Logo,

Não nos é dado nos impedir de nascer: mas podemos reparar esse erro - pois às vezes é um erro. Se alguém se elimina, faz a coisa mais respeitável que existe: com isso, quase se merece viver... A sociedade, que digo eu?, a vida mesma tira mais proveito disso que de alguma "vida" na renúncia, na anemia e outras virtudes - os outros foram poupados dessa visão, a vida foi poupada de uma objeção (Nietzsche, 2006, p.84-85)

Ora, se hoje nos pensamos como afastados temporalmente desta modernidade, se ela nos constitui como o mais próximo passado, o agente desta passagem foi, precisamente, o novo estatuto da técnica, que nos instalou numa nova e dupla realidade: a presencial e a ciberespacial, a segunda, seguramente, contaminando a primeira com seu modelo lógico baseado em informação e em banco de dados.

\section{Para alguns entusiastas das} novas tecnologias o corpo é um vestígio fadado a desaparecer de modo a permitir o acesso a uma humanidade gloriosa porque "consciência pura", livre da carne que a enraíza no mundo, limita suas experiências e sua permanência.

Neste novo universo, a promessa mais radical das tecnociências, especialmente das tecnologias ligadas à administração da vida, tem sido o afastamento da morte 
através de intervenções variadas que fazem da nossa era a de uma medicalização crescente. O desejo de morte, por sua vez, deve ser erradicado; por isto a melancolia e o sofrimento devem ser evitados ou "tratados": somos da geração Prozac.

Não causa espécie então que um suicídio cometido com divulgação em tempo real, servindo-se da mesma rede que capilariza o biopoder e suas resistências (que fazem parte dele, vale lembrar), atraia tanta atenção e mereça um estudo da relação entre biopoder, mídia e cibercultura.

Para retomar nosso ritmo associativo, o garoto que se suicidou na rede não fez uso dela apenas para adquirir informações sobre como produzir a própria morte. Entendendo-se como compositor, ele usava a WEB tanto para difundir suas músicas (além dos seus anseios suicidas) quanto para buscar e ouvir bandas consagradas, famosas pela qualidade de seus produtos e pelo caráter pesado e agressivo de suas composições e interpretações. Sob a alcunha de Yoñlu, Vinícius chegou alcançar alguma notoriedade a partir da divulgação de suas músicas pela Internet, a ponto de uma das faixas de seu CD, "Deskjet Remix", ter tido uma boa repercussão em festas eletrônicas de Londres, como indica a reportagem da Época.

As letras das canções de Vinícius são de certa forma reorganizações mais ou menos criativas de suas influências musicais, como na profética "Suicide Song": 'See, I' $m$ sad 'cause I' $m$ alone in this world and writing doesn't seem to help, Now she's gone like everyone I ever met, Now my suicide is lit by the sunset'. Hoje, há pelo menos treze comunidades no Orkut dedicadas à obra e à memória de Yoñlu. Poderíamos arriscar dizer que a rede funcionou, no caso Vinícius, simultaneamente como efeito e instrumento de sua morte estetizada.

\section{Considerações finais (não terminais)}

Voltando ao ponto de onde partimos, isto é, às matérias jornalísticas referentes à morte de Yoñlu (ou Vinicius) e às especulações sobre o Mal.com, algumas observações nos parecem interessantes para uma reflexão que ,efetivamente, pondere sobre a relação entre a WEB 2.0 e as novas formas de produção de subjetividade e sociabilidade, assim como seus efeitos no chamado mundo real.

Nosso primeiro interlocutor seria o psicanalista, do qual voltamos a louvar a coragem de reconhecer em público a falha que, em última instância, era também sua e ele teve que explicitar:

Subestimar o papel da Internet. Eu uso a Internet mas não a habito. Tem gente que mora dentro da Internet... Ele a habitava. Não vamos achar que a Internet é coisa ruim a priori. Ele construiu a obra dele na Internet, a troca de músicas que resultou no disco interessante que fez. A Internet possibilita encontros que antes não eram possíveis. É o paraíso dos solitários e dos tímidos. Por outro lado, ela possibilita também outro tipo de coisa que nunca aconteceria sem ela: o incremento de certas morbidades pela possibilidade de compartilhar e, a partir disso, de criar uma identidade (Época, 2008).

Eis a questão: a geração que chamamos neo-digital vive na rede ou realiza nesta, para o bem e para o mal, seus processos de projeção, identificação, estetização, glamourização e comunhão. Pais e terapeutas, desconhecendo esta realidade, incorrem em uma anacronia que impede que conheçam ou interajam com estes novos personagens, que são seus filhos e/ou pacientes. Da mesma maneira, nesta fala do Dr. Mário Corso encontramos um contraste curioso: ele reconheceu que a Internet possibilitou a divulgação das músicas e não percebeu na letra destas outra tentativa literário-musical de suicídio.

Se não fosse mórbido e desrespeitoso poderíamos dizer que algum domínio de análise dos discursos e uma atenção às afinidades eletivas do adolescente em questão teriam sido úteis, se não para evitar o suicídio em si, para compreendê-lo de maneira mais municiada. Assim como ajudaria a problematizar uma questão que se torna inarredável agora e da qual o caso é exemplo radical: qual o papel, o alcance e as possibilidades da psicanálise neste novo universo. Repensar este lugar é fundamental, e nos parece ser a mais proveitosa conseqüência deste episódio. Traria para a psicanálise e para a mídia em geral um espaço de tematização muito mais complexo, que inclui um dado bastante novo na experiência do Ocidente, que se relaciona com as idéias de corpo e experiência. Internet, ciberespaço, realidade virtual são novos modos de interação homem-máquina. A máquina é o novo ambiente da experiência. $\mathrm{Na}$ integração que se põe em movimento entre seres biológicos e maquínicos, corpo e pensamento, matéria viva e inerte, carne e silício, nossas referências tradicionais ficam abaladas.

O corpo não é a sede ou condição de possibilidade de estar no mundo. Para alguns entusiastas das novas tecnologias o corpo é um vestígio fadado a desaparecer de modo a permitir o acesso a uma humanidade gloriosa porque "consciência pura", livre da carne que a enraíza no mundo, limita suas experiências e sua permanência. Também parece ser assim para alguns "neo-digitais": já vimos na literatura teórica ${ }^{6}$ e nas conversas cotidianas que resumir o mundo das experiências àquelas que exigem um corpo é uma redução inaceitável, quando tantas coisas interessantes podem ser vividas sem necessitarem desta materialidade.

Neste universo onde o corpo é visto como limitação, vida e morte seriam a mesma coisa que foram nas sociedades que nos antecederam? As biotecnologias e a cibercultura não nos conduzem à construção de novas referências ou, pelo menos, à flexibilização das nossas 
mais caras certezas $\square$ FAMEcos

NOTAS

* Texto aprovado para o II Simpósio Nacional da ABCiber, ocorrido em Novembro de 2008, na cidade de São Paulo.

1 Sabemos que, para um psicanalista, perder um paciente pode soar como incompetência terapêutica.

2 Vemos aí a oportunidade para pensar também no que consideramos máquinas de guerra, pois, a nosso ver, a questão para Deleuze nunca teve cunho moral; a potência de destruição também é figura de uma vontade, pode ser o impulso de uma força ativa.

3 É o caso explícito dos estóicos.

4 Estamos empregando multiplicidade na esteira do pensamento de Deleuze, indicando menos uma diversidade do que a substituição da conjunção alternativa ou pela conjunção aditiva e, produzindo assim uma outra operação de sentido.

5 O próprio Foucault, no precioso texto O que é o Iluminismo?, descrevendo a leitura de Kant da Revolução, mostra que o que ele encontrava era menos o projeto político de transformação e mais a adesão entusiasmada de um povo, o que corrobora nossas propostas de pensar como um e.

6 A este respeito ainda é válido o já antigo texto da TURKLE, Sherry. Life on the screen.

\section{REFERÊNCIAS}

AZEVEDO, Solange \& BRUM, Eliane. Suicídio.com. Sites na internet incentivam adolescentes como o gaúcho Yoñlu a se matar e ajudam a escolher o método. Revista Época. Rio de Janeiro, $\mathrm{n}^{\circ} 508$, fev 2008. Disponível em <http:/ / revistaepoca.globo. com/RevistaEpoca/0,EDG81603-6014-508-1,00. $\mathrm{html}>$. Acesso em 03 out 2008.

BATAILLE, Georges. Sade et l'homme normal. In: L'Erotisme. Paris: Ed de Minuit, 1957.

DELEUZE, Gilles. Conversações. Rio de Janeiro: Ed 34, 1992.

DELEUZE, Gilles \& PARNET, Claire. Diálogos. Lisboa: Relógio d'água, 2004.

DURKHEIM, Émile. Le suicide. Étude sociologique. Québec: L'Université du Québec, 2002. Disponível em <http://classiques.uqac.ca/ classiques/Durkheim_emile/suicide/suicide. html>. Acesso em 04 out 2008.

FOUCAULT, Michel. Direito de morte e poder sobre a vida. In: História da sexualidade - A vontade de saber. Vol I. Rio de Janeiro: Graal, 2006.

Introdução: modificações. In: História da Sexualidade II - O uso dos prazeres. Rio de Janeiro: Graal, 1994.

. O que é o Iluminismo? In: ESCOBAR, C. H. (Org.). M. Foucault, 1926/1984. O dossier: últimas entrevistas. Rio de Janeiro: Taurus, 1984.

NIETZSCHE, Friedrich. Da morte livre. In: Assim falou Zaratustra. São Paulo: Martin Claret, 2002.

. Incursões de um extemporâneo. In: Crepúsculo dos ídolos - ou como se filosofa com o martelo. São Paulo: Companhia das Letras, 2006.

PUENTE, Fernando Rey (Org.). Os filósofos e o suicídio. Rio de Janeiro: Travessias, 2008.

TARDE, Gabriel. Contre Durkheim à propos de son suicide. In: BERLANDI, Massimo \& CHERKAOUI, Mohamed. Le Suicide un siècle après Durkheim. Paris: Les Presses Universitaires de France, 2000.

TIRABOSCHI, Juliana. Mal. com: o lado sombrio da internet. Revista Galileu. Rio de Janeiro, $\mathrm{n}^{\mathrm{o}} 201$, abr 2008.

TURKLE, Sherry. A vida no écran: a identidade na era da internet. Lisboa: Relógio d'Água, 1997.

TUCHERMAN, Ieda. Corpo e narrativa cinematográfica. Corpo, Técnica, Subjetividade. In: Revista de Comunicação e Linguagens. Lisboa: Relógio d'Agua, p.187-198, 2004. 